ECCOMAS

Proceedia
M. Papadrakakis, M. Fragiadakis (eds.) Streamed from Athens, Greece, 28 - 30 June 2021

\title{
INFLUENCE OF SCOUR ON DYNAMIC IMPEDANCES OF BRIDGE SHALLOW FOUNDATIONS
}

\author{
C. Antonopoulos ${ }^{1}$, E. Tubaldi ${ }^{1}$, S. Carbonari ${ }^{2}$, F. Gara ${ }^{2}$, and F. Dezi ${ }^{3}$ \\ ${ }^{1}$ Department of Civil and Environmental Engineering \\ University of Strathclyde \\ Glasgow, Scotland \\ e-mail: \{christos.antonopoulos,enrico.tubaldi\}@strath.ac.uk \\ ${ }^{2}$ Department of Construction, Civil Engineering and Architecture (DICEA) \\ Università Politecnica delle Marche \\ Ancona, Italy \\ \{s.carbonari,f.gara\}@staff.univpm.it \\ ${ }^{3}$ Department of Economics, Science and Law (DESD) \\ University of the Republic of San Marino \\ Republic of San Marino \\ francesca.dezi@unirsm.sm
}

\begin{abstract}
Many bridges in earthquake-prone countries cross waterways and have foundations in riverbeds, and thus are exposed to flood, which may cause scour and a change of the bridge dynamics. The present study illustrates a modeling strategy for investigating numerically the influence of scour on the dynamic behaviour of bridges with scoured shallow foundations. The proposed strategy is based on the evaluation of the impedance functions of a massless rigid foundation resting on an elastic half-space under increasing depths of scour. The derived impedance functions are used to evaluate the effects of scour on the dynamic behaviour of a Soil-Foundation-Structure system representative of a bridge pier. In particular, the changes in the fundamental vibration period due to scour are investigated. The results of the study can be used for developing vibration-based scour detection techniques and for investigating the seismic response of scoured bridges.
\end{abstract}

Keywords: Scour, Bridges, Soil-structure Interaction, Foundation Impedances

ISSN:2623-3347 (C) 2021 The Authors. Published by Eccomas Proceedia. Peer-review under responsibility of the organizing committee of COMPDYN 2021. doi: 10.7712/120121.8737.19332 


\section{INTRODUCTION}

Scour is the first cause of bridge failure worldwide [1-3], inducing not only traffic disruption but also significant socio-economic losses and fatalities [4-6]. Bridge scour is the erosion of sediments around bridge piers and abutments due to flowing water. Scour can be classified into natural, contraction and local scour, being the latter the most critical one. Particularly, local scour is formed due to local features, such as bridge piers and abutments, that obstruct the flow, leading to increased local flow velocities and turbulence levels that result in vortices and thus in local sediment movements and erosion around underwater foundations [7]. Scour may cause a significant loss of foundation carrying capacity $[8,9]$ and a reduction of the stiffness of bridges [10-16]. A great number of bridges worldwide, such as masonry-arch bridges, has shallow foundations that are more vulnerable to scour in comparison with those with deep foundations. Interestingly, the majority of the studies in the literature focus on the effects of scour on bridges with deep foundations, whereas studies related to bridges with shallow foundations are quite limited. Only recently, some research efforts have aimed at filling this knowledge gap [17-19].

Scour causes a change of the global stiffness of bridges, and thus a different response to dynamic loadings, such as earthquakes. In particular, scour can alter dramatically both the kinematic and the inertial soil-structure interaction, resulting in a reduction of the fundamental vibration frequency. There are several studies about the combined effect of scour and earthquake hazard on the dynamic properties of bridges [20-22], however most of them focus on bridges with deep foundations. To account for soil-foundation-structure (SFS) interaction effects, the sub-structure approach is usually employed, simulating the soil-foundation system in inertial interaction analyses through impedance functions [23-25]. These functions represent the frequency dependent stiffness and damping characteristics of soil-foundation system and govern relationships between forces and displacements of the compliant restraints at the foundation level. To the author's knowledge, only Guo [18] investigated the seismic response of bridges with scoured shallow foundations. Specifically, the foundation impedance functions were calculated under scour hazard, which led to a reduction of the foundation stiffness and radiation damping. It was found that scour reduces seismic force demands but may increase the displacement demands. Given the existence of a great number of bridge footings on shallow foundations in earthquake-prone countries and the current frequent occurrence of extreme weather events, further research on the effects of scour on the dynamic response of bridges is imperative.

This study investigates numerically the impact of scour on the dynamic response of bridges with shallow foundations. For this purpose, the case of a massless rigid strip foundation resting on a homogenous elastic half-space is modelled in Abaqus [26] under various scour scenarios to estimate the impedance functions of the soil-foundation system. Subsequently, the derived impedance functions are used to evaluate the dynamic behavior of a SFS systems, representative of a bridge pier, with particular focus on the fundamental vibration frequency.

\section{NUMERICAL ESTIMATION OF FOUNDATIONS IMPEDANCES}

In this section, a massless rigid strip foundation resting on a homogenous elastic soil domain is investigated. For the sake of simplification, a plane-strain problem assumption is made, based on taking into account the aspect ratios of masonry bridge's piers characterized by a slender rectangular shape. The model developed in Abaqus is firstly validated with numerical analytical solutions provided by Hryniewicz [23] and then adopted for the estimation of the impedance functions considering various scour profiles. 


\subsection{Finite element model}

The modelling strategy developed in Abaqus for the estimation of impedance functions of the studied strip foundation is described in this subsection. The impedance functions can be expressed in non-dimensional form as a function of the non-dimensional frequency $a_{0}=\frac{\omega b_{f}}{V_{s}}$, where $\omega$ is the circular frequency of the excitation, $b_{f}$ the half width of the foundation, and $V_{s}$ the shear wave velocity.

The dimensions of the finite soil domain are assumed to be $125 \times 62.5 \mathrm{~m}$, while infinite elements are placed at the boundaries in order to satisfy the radiation condition preventing wave reflections (Figure 1i). These infinite elements are long strips with width equal to the half width of the soil domain, i.e. $62.5 \mathrm{~m}$. Since a plane-strain assumption is made, the soil domain consists of four node plane-strain elements (CPE4), whereas the boundaries consists of plane-strain solid continuum infinite elements (CINPE4). The soil is characterized by a Young modulus $(E)$, Poisson's ratio $(v)$ and density $(\rho)$ equal to $162.41 \mathrm{MPa}, 0.25$ and $1600 \mathrm{~kg} / \mathrm{m}^{3}$, respectively. The rigid strip foundation with width $2 b_{f}=1 \mathrm{~m}$ is simulated through a rigid-body constrain applied to the set of nodes belonging to the soil-foundation interface (at the ground surface). Considering that the estimated impedance functions are presented in a non-dimensional form, the selected values for the characteristics of the soil and foundation do not affect the results but are herein indicated because they have to comply with the adopted mesh for convergence issues. Indeed, in order to accurately capture the wave propagation, the mesh size of the soil domain should satisfy the following relation $[27,28]$ :

$$
l_{\max } \leq \frac{\lambda_{\min }}{10} \leq \frac{V_{s, \min }}{10 f_{\max }}
$$

where $l_{\max }$ is the maximum element size, $\lambda_{\min }$ is the shear wavelength and $f_{\max }$ is the maximum frequency of interest, which, for seismic applications, is typically within the range $0-15 \mathrm{~Hz}$. For a given element size, the maximum dimensionless excitation frequency $a_{0}$ satisfies:

$$
a_{0} \leq \frac{2 \pi b_{f}}{10 l_{\max }}
$$

It is worth noting that a $1 \%$ damping ratio is added with a Rayleigh model to the soil domain in order to lessen the numerical fluctuation of the results. Considering above requirements, a refined mesh around the foundation is employed. Specifically, a square mesh $0.005 \times 0.005(\mathrm{~m})$ and $0.025 \times 0.025(\mathrm{~m})$ is used nearby the left and right sides of the foundation, respectively. The different mesh sizes at each part of the foundation aim at reducing the computational cost and facilitating the removal of elements at the next stages for the various scour simulations (see Section 2.4.). In the rest of the soil domain, a bias mesh towards to the boundaries is used with maximum element size $l_{\max }=0.3 \mathrm{~m}$.

\subsection{Methodology}

The impedance functions are estimated by means of steady-state analyses by applying harmonic unit amplitude displacements at the centroid of the foundation (master node) and by measuring the corresponding harmonic reaction forces (Figure 1ii). The harmonic motion of the master node can be expressed with the following equation: 


$$
\left[\begin{array}{c}
P(\omega) \\
Q(\omega) \\
M(\omega) / b_{f}
\end{array}\right]=\left[\begin{array}{ccc}
k_{z z}+i d_{z z} & 0 & 0 \\
0 & k_{x x}+i d_{x x} & k_{x r_{y}}+i d_{x r_{y}} \\
0 & k_{x r_{y}}+i d_{x r_{y}} & k_{r_{y} r_{y}}+i d_{r_{y} r_{y}}
\end{array}\right]\left[\begin{array}{c}
w_{0}(\omega) \\
u_{0}(\omega) \\
\varphi_{0}(\omega) b_{f}
\end{array}\right]
$$

where $w_{0}, u_{0}$ are the displacement amplitudes along the $z$ and $x$ directions, respectively, $\varphi_{0}$ is the rotation amplitude, and $k_{i j}, d_{i j}=c_{i j} \omega$ are frequency-dependent quantities describing the real and the imaginary parts of the impedance functions, respectively, for the foundation response in the $i$-th direction due to the excitation in the $j$-th direction. Figure 2 illustrates forces and displacements along the various directions. The coefficients $k_{i j}$ and $d_{i j}$ evaluated numerically are presented as a function of the dimensionless frequency $a_{0}$ and compared with the analytical estimates obtained by Hryniewicz [23]. This procedure will be also repeated for two scour layouts, characterized by different geometries (see Section 2.4.).

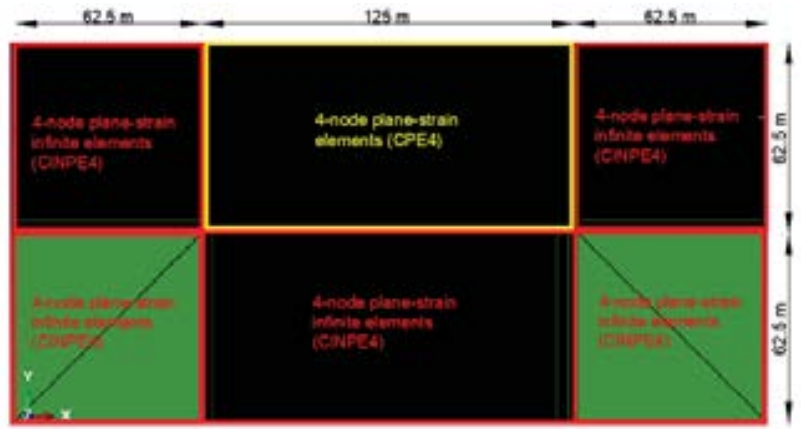

(i)

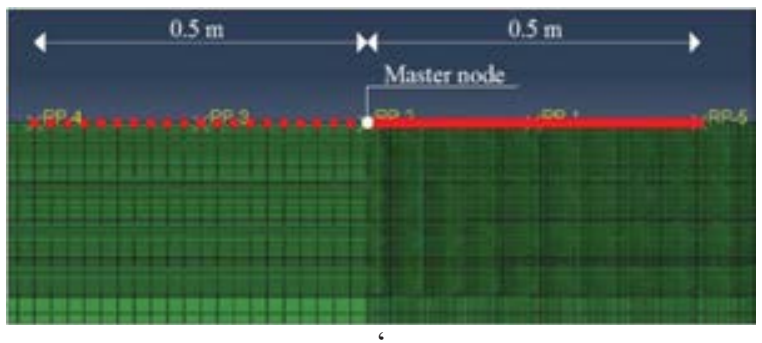

(ii)

Figure 1: (i) FE model of the soil domain with infinite elements at boundaries, (ii) Rigid-body constraint used to simulate the massless rigid strip foundation.

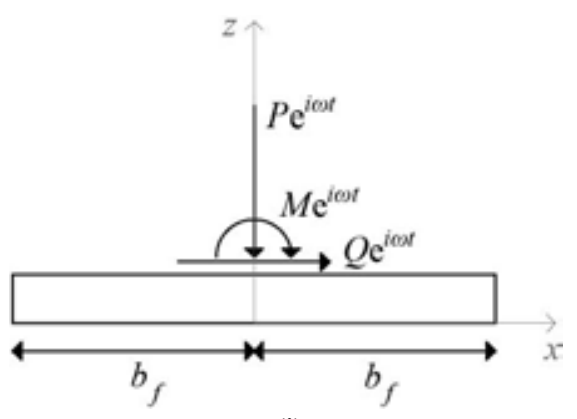

(i)

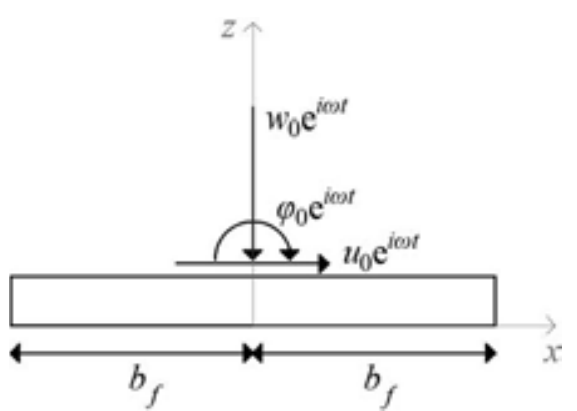

(ii)

Figure 2: (i) Forces and (ii) displacements of the strip foundation.

\subsection{Validation of numerical model}

In this subsection, the previously described numerical model is validated by comparing the derived impedance functions with those obtained by Hryniewicz [23]. It is noteworthy that in Hryniewicz [23] the coupling between the horizontal and rotational response of the foundation is neglected (i.e. $k_{x r_{y}}=0, d_{x r_{y}}=0$ ). However, this effect is expected to be not significant and for this reason in the numerical study the rotation of the master node is restrained when a unit horizontal displacement is applied and vice-versa. The harmonic analyses are carried out for frequencies in the range between $3.2 \mathrm{~Hz}$ and $200 \mathrm{~Hz}$, corresponding to values of the dimensionless frequency $a_{0}$ between 0.05 and 3.11. The derived impedance functions (NS-IC) 
are depicted and compared with Hryniewz's ones in Figure 3. The acronym NS stands for the case of "No Scour".

In general, the derived real and imaginary parts of the impedance functions converge with the analytically estimated ones. Nevertheless, some differences are observed for the real part of the rotational behaviour $\left(k_{r_{y} r_{y}}\right)$, which may be due to the approximation introduced by Hryniewicz [23] for deriving the problem solution. As mentioned before, the maximum element size of the finite soil domain is $l_{\max }=0.3 \mathrm{~m}$, which, according to Eq. 2, leads to a maximum dimensionless frequency $a_{0}=1.05$. However, the application of a biased mesh around the foundation with element size significantly smaller than $l_{\max }$ results in a satisfactory agreement between the derived and analytical data also for higher frequencies (up to $a_{0, \max }=3.11$ ).

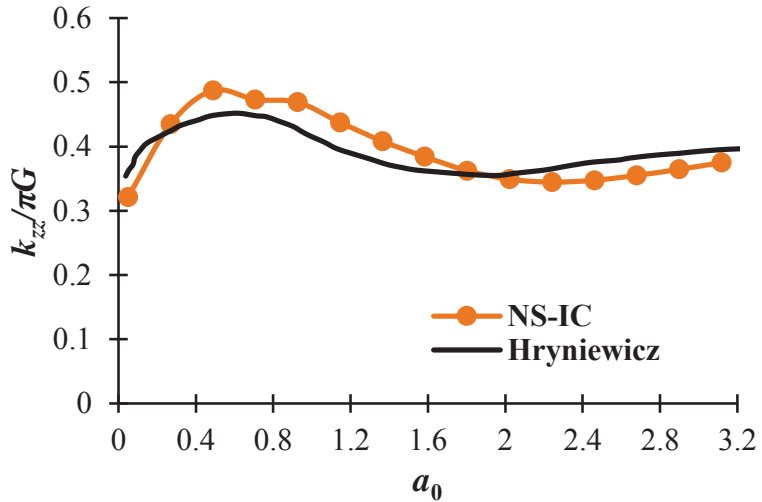

(i)

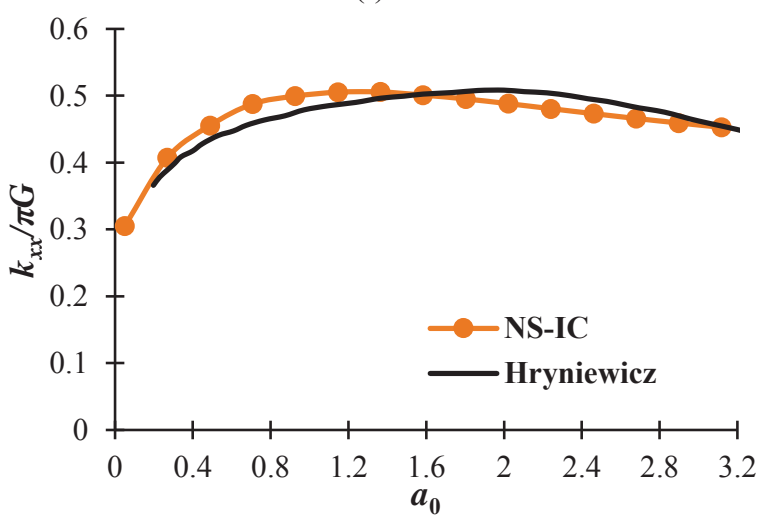

(iii)

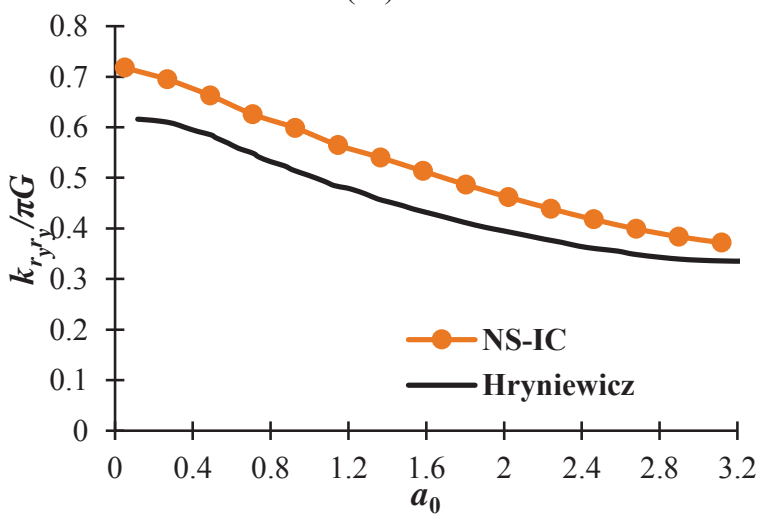

(v)

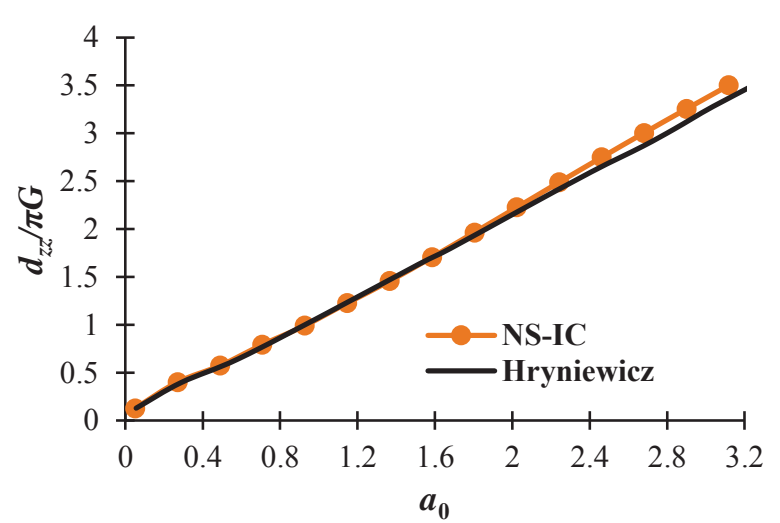

(ii)

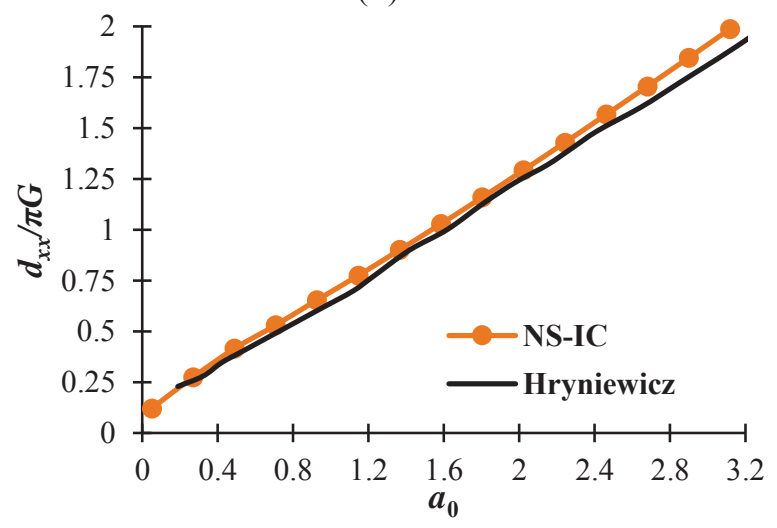

(iv)

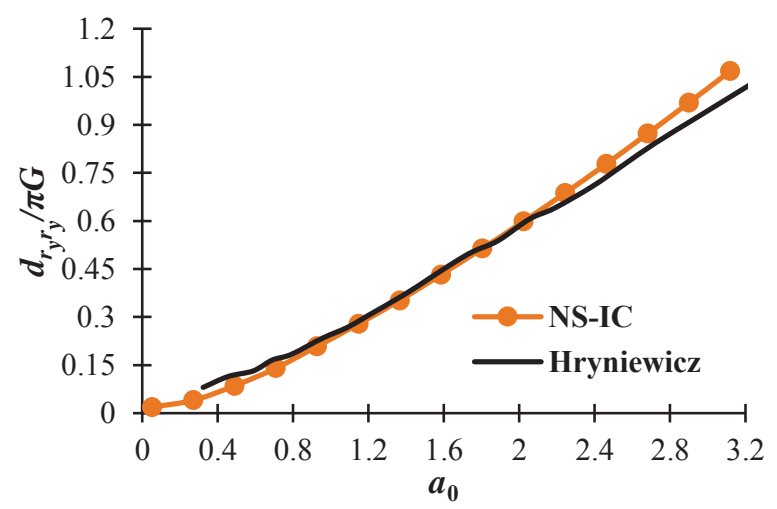

(vi)

Figure 3: Comparisons of impedance functions obtained numerically (NS-IC) with those developed by Hryniewicz (i) $k_{z z}$, (ii) $d_{z z}$, (iii) $k_{x x}$, (iv) $d_{x x}$, (v) $k_{r y r y}$, (vi) $d_{r y r y}$. 


\subsection{Impact of scour on the foundation impedances}

This subsection investigates the changes of the impedance functions of the foundation due to scour. Specifically, two triangular shaped scour scenarios with different widths and depths are considered, corresponding to one fourth (denoted as TS1/4) and three eighth (denoted as TS3/8) of the width of the foundation subjected to scour (Figure 4), respectively. Moreover, the upstream scour hole slope is assumed equal to $\varphi=30^{\circ}$, whereas the downstream scour slope is approximately half of the upstream slope [29].

The impedance functions of the foundation under the various scour scenarios are derived by removing the corresponding finite elements from the soil domain beneath the foundation and rerunning the harmonic analyses. It must be mentioned that the results are obtained by taking the coupling phenomenon between the horizontal and rotation response of the foundation into account (Figure 5). In general, it can be noticed that increasing the scour hole dimensions leads to a reduction of both real and imaginary components of the impedance functions for low frequencies. On the other hand, for high values of $a_{0}$, increasing the scour depth and width results in an increase of the real part of the impedance functions. Moreover, it is remarkable that the values of the vertical real component $\left(k_{z z}\right)$ are higher than the case of no scour for higher frequencies.

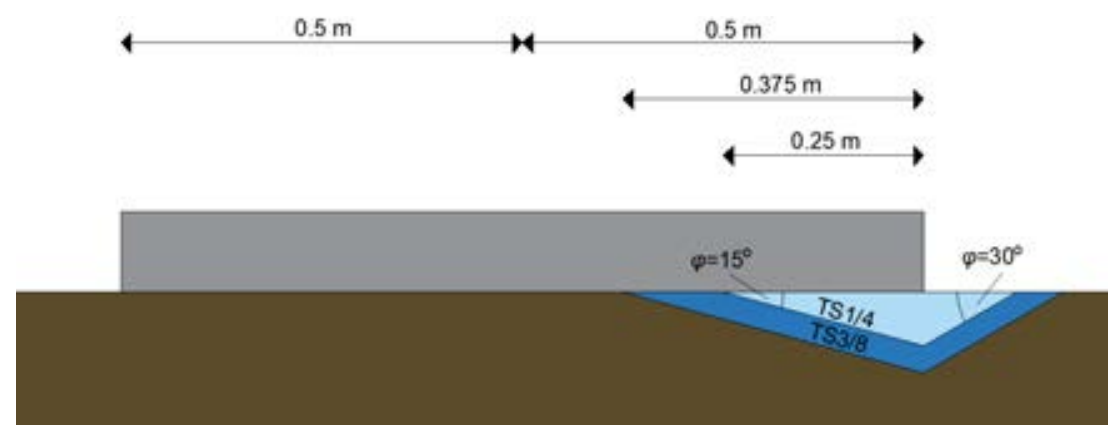

Figure 4: Geometry of the 3 different scour hole scenarios investigated.

\section{IMPACT OF SCOUR ON FUNDAMENTAL VIBRATION FREQUENCY OF A SFS SYSTEM}

The foundation impedance functions for various scour scenarios estimated in Section 2, are herein used to investigate the impact of scour on the fundamental vibration frequency of a SFS system, representative of a bridge pier. Initially, the formulation of the dynamic problem is presented, and then the fundamental vibration frequency of the SFS system is calculated solving the eigenvalue problem for different levels of scour.

\subsection{Problem formulation for SFS system with scoured foundations}

The considered SFS model consists of a superstructure with lumped mass $m_{s}$, lateral stiffness $k_{s}$, height $h_{s}$, and a foundation with mass $m_{f}$, height $2 h_{f}$, width $2 b_{f}$ and mass moment of Inertia $I_{f}$ (Figure 6). The foundation rests on a soil domain with shear modulus $G$, mass density $\rho$ and Poisson's ratio $v$, while the soil-foundation compliance is expressed through the already calculated impedance functions (see Section 2.4.). The system has three degrees of freedom, namely the foundation translation $\left(u_{f}\right)$ and rotation $\left(\theta_{f}\right)$, and the relative displacement $u_{s}$ of mass $m_{s}$ with respect to the base. 


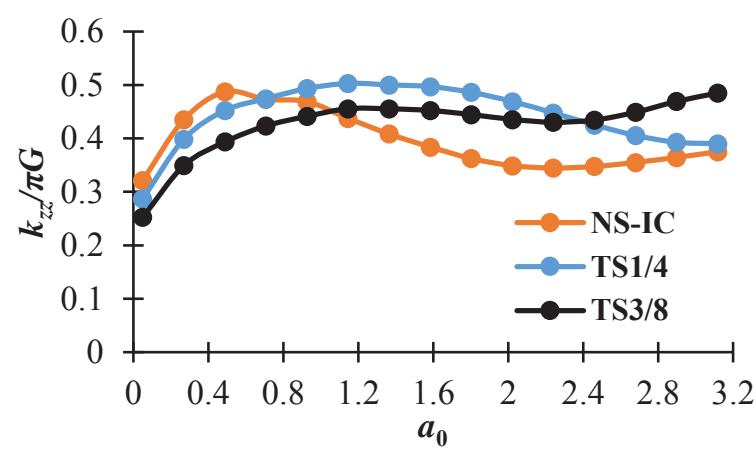

(i)

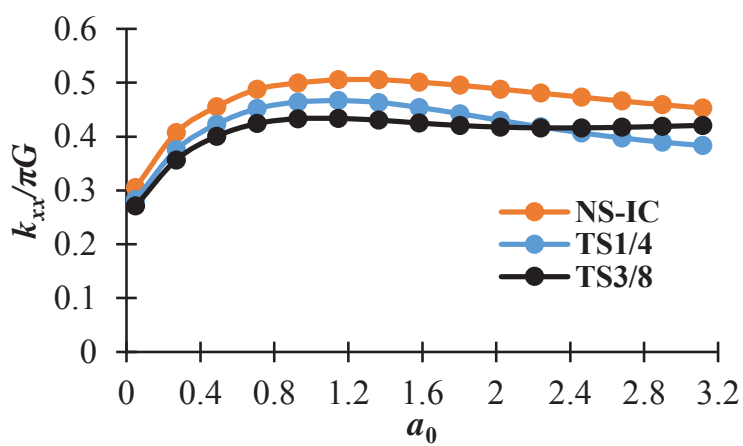

(iii)

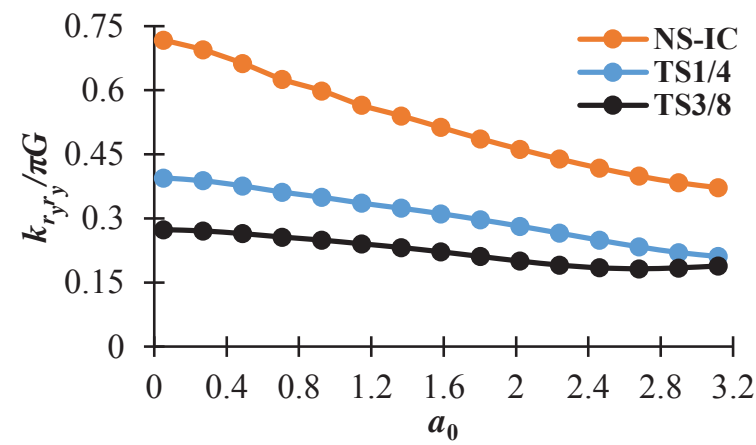

(v)

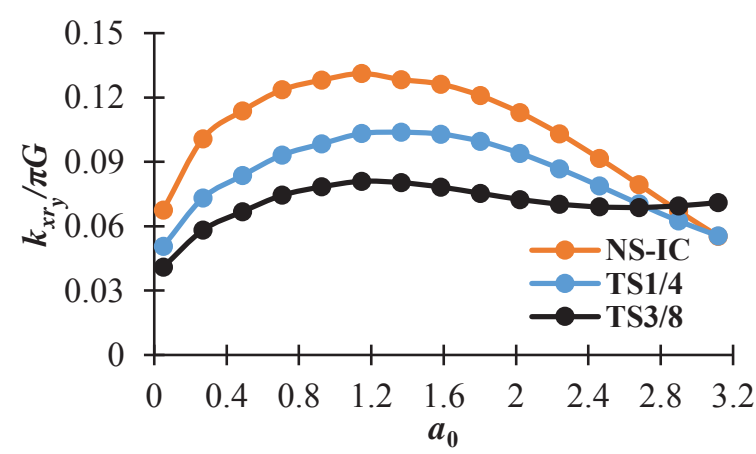

(vii)

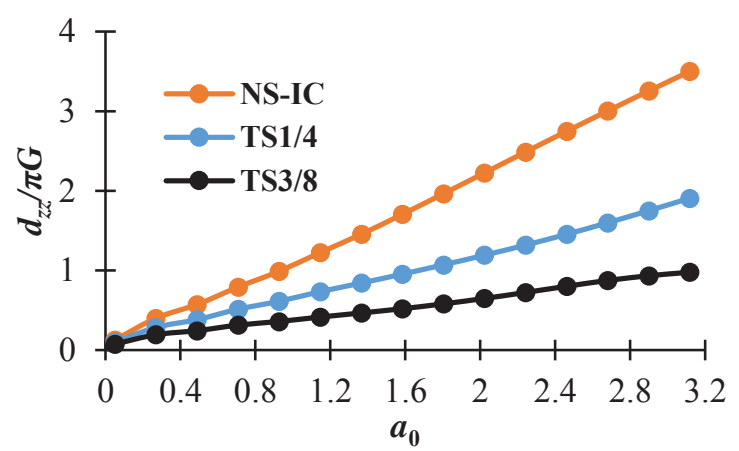

(ii)

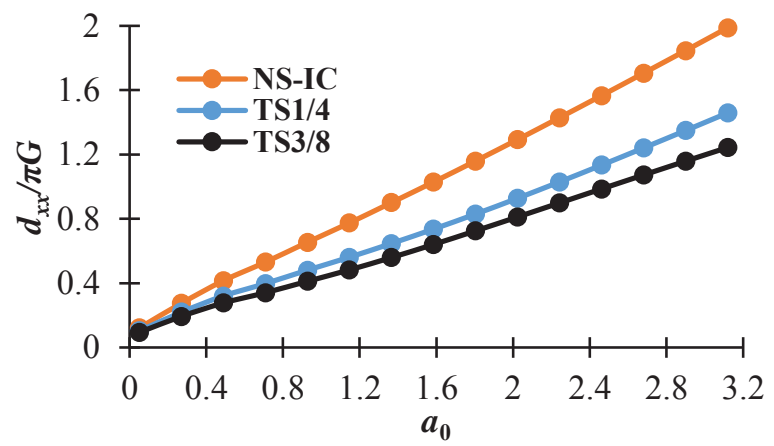

(iv)

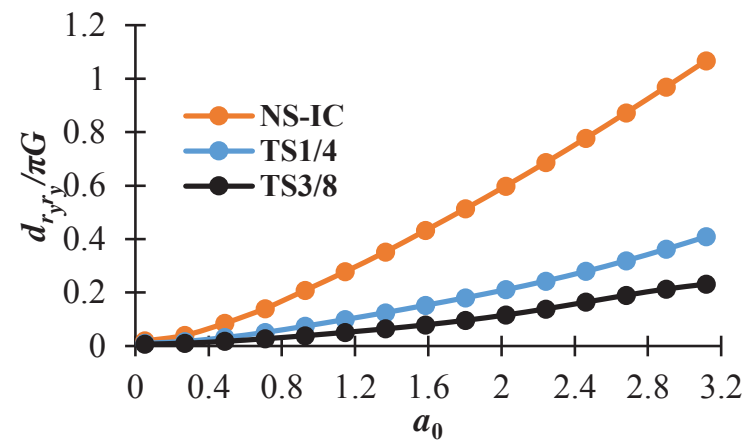

(vi)

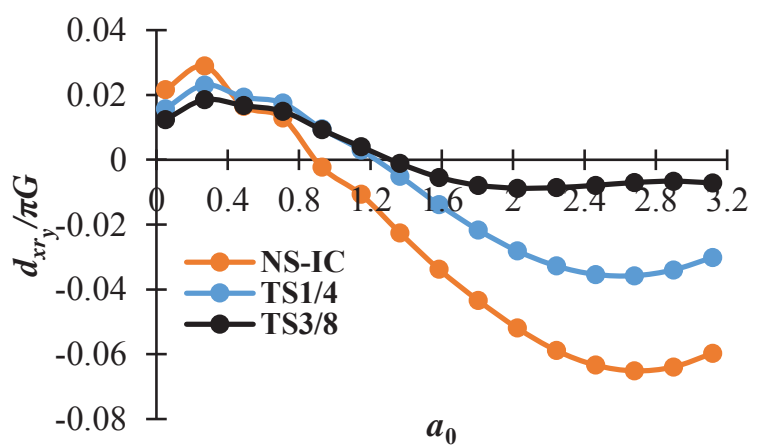

(viii)

Figure 5: Comparisons of the calculated impedance functions for different scour scenarios (i) $k_{z z}$, (ii) $c_{z z}$, (iii) $k_{x x}$, (iv) $c_{x x}$, (v) $k_{r y r y}$, (vi) $c_{r y r y}$, (vii) $k_{x r y}$, (viii) $c_{x r y}$ 


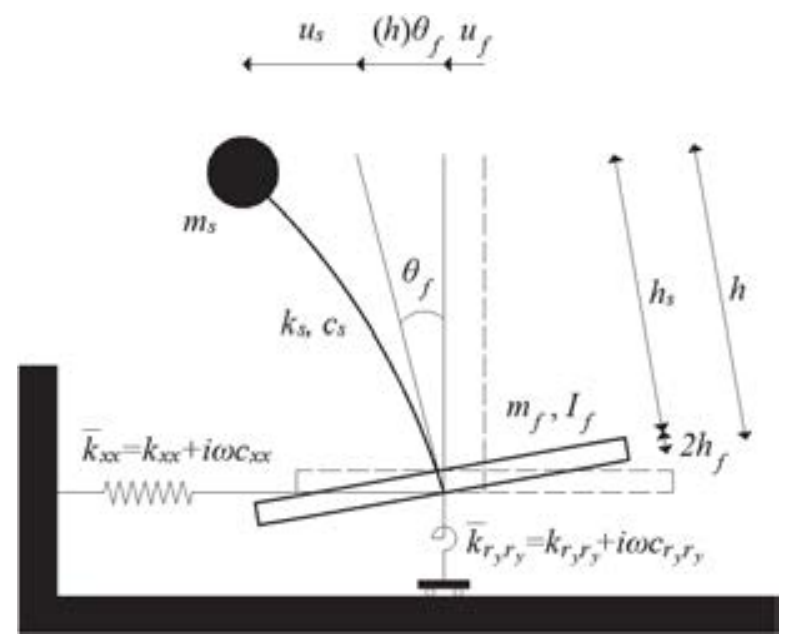

Figure 6: Model of the SFS system (coupling terms are not illustrated).

The equation of motion of the free vibrations for the above described SFS system can be expressed in the frequency domain in a vector form as:

$$
-\omega^{2} \mathbf{M} \overline{\mathbf{U}}+\mathrm{i} \omega \mathbf{C}(\omega) \overline{\mathbf{U}}+\mathbf{K}(\omega) \overline{\mathbf{U}}=0
$$

where $\overline{\mathbf{U}}$ denotes the Fourier transform of the vector collecting the system translational and rotational degrees of freedom, while $\mathbf{M}, \mathbf{C}$ and $\mathbf{K}$ are the mass, damping and stiffness matrices of the system, respectively. Vector and matrices appearing in Eq. 4 are expressed as follows [30]:

$$
\begin{gathered}
\mathbf{U}=\left[\begin{array}{lll}
u_{f} & \theta_{f} & u_{s}
\end{array}\right]^{T} \\
\mathbf{M}=\left[\begin{array}{ccc}
m_{f}+m_{s} & m_{f} h_{f}+m_{s} h & m_{s} \\
m_{f} h_{f}+m_{s} h & I_{f}+m_{f} h_{f}^{2}+m_{s} h^{2} & m_{s} h \\
m_{s} & m_{s} h & m_{s}
\end{array}\right] \\
\mathbf{C}(\omega)=\left[\begin{array}{ccc}
c_{x x}(\omega) & b_{f} c_{x r_{y}}(\omega) & 0 \\
b_{f} c_{x r_{y}}(\omega) & b_{f}^{2} c_{r_{y} r_{y}}(\omega) & 0 \\
0 & 0 & c_{s}
\end{array}\right] \\
\mathbf{K}(\omega)=\left[\begin{array}{ccc}
k_{x x}(\omega) & b_{f} k_{x r_{y}}(\omega) & 0 \\
b_{f} k_{x r_{y}}(\omega) & b_{f}^{2} k_{r_{y} r_{y}}(\omega) & 0 \\
0 & 0 & k_{s}
\end{array}\right]
\end{gathered}
$$

For the sake of simplicity, the damping of the system is neglected by assuming the imaginary parts of the impedance functions to be zero. Therefore, the fundamental vibration frequency of the system can be found by solving the eigenvalue problem of Eq. 4, which can be rewritten as follows:

$$
\begin{gathered}
-\omega^{2} m_{s}\left(\bar{u}_{f}+h \bar{\theta}_{f}+\bar{u}_{s}\right)-\omega^{2} m_{f}\left(\bar{u}_{f}+h_{f} \bar{\theta}_{f}\right)+\bar{k}_{x x} \bar{u}_{f}+b_{f} \bar{k}_{x r_{y}} \bar{\theta}_{f}=0 \\
-\omega^{2} m_{s} h\left(\bar{u}_{f}+h \bar{\theta}_{f}+\bar{u}_{s}\right)-\omega^{2} I_{f} \bar{\theta}_{f}-\omega^{2} m_{f} h_{f}\left(\bar{u}_{f}+h_{f} \bar{\theta}_{f}\right)+b_{f} \bar{k}_{x r_{y}} \bar{u}_{f}+b_{f}^{2} \bar{k}_{r_{y} r_{y}} \bar{\theta}_{f}=0 \\
-\omega^{2} m_{s}\left(\bar{u}_{f}+h \bar{\theta}_{f}+\bar{u}_{s}\right)+\bar{k}_{s} \bar{u}_{s}=0
\end{gathered}
$$


where $\bar{k}$ contains both the real and imaginary part of the impedances $\left(\bar{k}_{i j}=k_{i j}+i \omega c_{i j}\right)$.

Eq. 9i and Eq. 9iii can be written as:

$$
\begin{gathered}
\bar{\theta}_{f}=-\frac{\omega^{2} m_{s}\left(\bar{u}_{f}+\bar{u}_{s}\right)-\bar{k}_{x x} \bar{u}_{f}+\omega^{2} m_{f} \bar{u}_{f}}{-b_{f} \bar{k}_{x r_{y}}+h \omega^{2} m_{s}+h_{f} \omega^{2} m_{f}} \\
\bar{\theta}_{f}=\frac{\bar{k}_{s} \bar{u}_{s}-\omega^{2} m_{s}\left(\bar{u}_{f}+\bar{u}_{s}\right)}{h \omega^{2} m_{s}}
\end{gathered}
$$

Equating Eq. 10 and Eq. 11 one obtains:

$$
\bar{u}_{f}=\frac{\frac{\bar{k}_{s} \bar{u}_{s}-\omega^{2} m_{s} \bar{u}_{s}}{h \omega^{2} m_{s}}+\frac{\omega^{2} m_{s} \bar{u}_{s}}{-b_{f} \bar{k}_{x r_{y}}+h \omega^{2} m_{s}+h_{f} \omega^{2} m_{f}}}{\frac{1}{h}-\frac{\omega^{2} m_{f}-\bar{k}_{x x}+\omega^{2} m_{s}}{-b_{f} \bar{k}_{x r_{y}}+h \omega^{2} m_{s}+h_{f} \omega^{2} m_{f}}}
$$

Entering Eq. 12 into Eq. 11 yields:

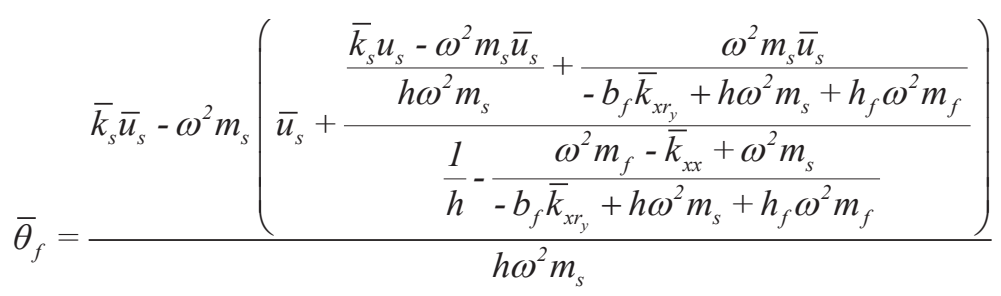

Entering Eq. 12 and Eq. 13 into Eq. 9ii finally gives the following homogeneous equation:

$$
(\alpha+\beta+\gamma) \bar{u}_{s}=0
$$

where:

$$
\begin{gathered}
\alpha=\left(-b_{f} \bar{k}_{x r_{y}}+h_{f} m_{f} \omega^{2}+h m_{s} \omega^{2}\right) \delta \\
\beta=\left(b_{f}^{2} \bar{k}_{r_{y} r_{y}}-h^{2} m_{s} \omega^{2}-h_{f}^{2} m_{f} \omega^{2}-I_{f} \omega^{2}\right) \frac{\bar{k}_{s}-m_{s} \omega^{2}(1-\delta)}{h m_{s} \omega^{2}} \\
\gamma=-h m_{s} \omega^{2} \\
\delta=\frac{\frac{\bar{k}_{s}-m_{s} \omega^{2}}{h m_{s} \omega^{2}}-\frac{m_{s} \omega^{2}}{b_{f} \bar{k}_{x r_{y}}-h m_{s} \omega^{2}-h_{f} m_{f} \omega^{2}}}{\frac{\bar{k}_{x x}-m_{f} \omega^{2}-m_{s} \omega^{2}}{b_{f} \bar{k}_{x r_{y}}-h m_{s} \omega^{2}-h_{f} m_{f} \omega^{2}}-\frac{1}{h}}
\end{gathered}
$$

The solution of the eigenvalue problem described by Eq. 14 is elaborate, since impedances $k_{x x}, k_{x r_{y}}, k_{r_{y} r_{y}}$ are functions of the excitation frequency and depend on $G, V_{s}, b_{f}$. In literature there are various approaches for solving this eigenvalue problem, and thus to evaluate the system resonance frequency $\tilde{\omega}$ (see e.g. [31, 32]). In this paper, the resonance frequency is derived by solving repeatedly Eq. 14. In more detail, each time Eq. 14 is solved for the values 
of the impedance function $k_{x x}, k_{x r_{y}}, k_{r_{y} r_{y}}$ which correspond to a specific excitation of frequency $\omega$. The one for which $\omega=\widetilde{\omega}$ is the solution of the problem.

The above described procedure is implemented considering a SFS whose properties are consistent with the the EuroProteas' prototype [33]. The superstructure is characterised by a height $h_{s}=4.2 \mathrm{~m}$, lateral stiffness $k_{s}=2672.16 \mathrm{kN} / \mathrm{m}^{2}$, mass $m_{s}=6.11 \mathrm{ton} / \mathrm{m}$ and it is based on a strip foundation with width $2 b_{f}=3 \mathrm{~m}$, thickness $2 h_{f}=0.4 \mathrm{~m}$ mass $m_{f}=3.05 \mathrm{ton} / \mathrm{m}$ and moment of inertia $I_{f}=2.33$ ton $\cdot \mathrm{m}^{2} / \mathrm{m}$. The soil beneath the foundation is described by a shear modulus $G=31.47 \mathrm{MPa}$ and shear wave velocity $V_{s}=130 \mathrm{~m} / \mathrm{s}$. Figure 7 illustrates the values of the fundamental frequency of the system for different levels of scour, calculated using the impedance functions of Section 2. It can be observed that the natural frequency of the system decreases linearly for increasing widths and thus depths of scour. The reduction of frequency is of the order of $30 \%$ when the width of the scour hole beneath the foundation is about $1 / 3$ of the foundation total width.

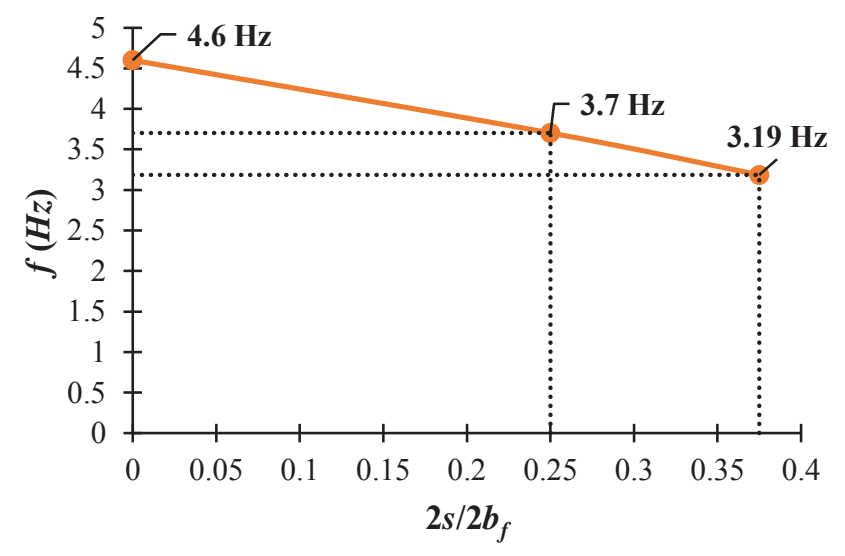

Figure 7: Fundamental vibration frequency of the SFS system for four different scour scenarios.

\section{CONCLUSIONS}

The impact of scour on the dynamic behaviour of bridges has been studied in this paper, by considering a soil-foundation-structure (SFS) system representative of a bridge pier. This SFS system consists of a single degree of freedom superstructure on a rigid strip foundation resting on an elastic soil domain. Initially, a massless rigid strip foundation is simulated in Abaqus to calculate its impedance functions in the case of no scour. Subsequently, the model is validated by comparing the derived impedance functions with the analytical estimates obtained by Hryniewicz [23]. Consequently, the model is used for a numerical investigation of the effects of scour on impedances, considering two scour scenarios with increasing width and depth. Based on the results of this study, the following conclusions can be drawn:

- In general, the foundation impedances are affected differently by scour, depending on the scour hole size and excitation frequency.

- The values of both the real and imaginary parts of the impedance functions decrease for increasing scour width (and thus depth) at low frequencies. On the other hand, for high frequencies a clear general trend cannot be identified, since scour affects the various components differently.

In the second part of the paper, the derived impedance functions are used to investigate the impact of scour on the fundamental vibration frequency of a SFS system, representative of a bridge pier. A linear decrease of the vibration frequency of the system is observed for increasing widths of scour. The variations of frequency are quite significant. 
The results of this study can be used to develop inverse techniques for evaluating the extent of scour beneath bridge foundations based on an estimation of the changes of the vibration frequency of SFS systems. Future studies will consider a wider range of SFS systems and also three-dimensional models for the bridges and the soil domain.

\section{ACKNOWLEDGEMENTS}

This work was supported by funding from the National Centre for Resilience (project title "Evaluating the benefit of structural health monitoring for improving bridge resilience against scour") and by the Scottish Road Research Board (project title "Decision Support System based on "adaptive" Flood Level Markers").

\section{REFERENCES}

[1] A.M. Shirole, R.C. Holt, Planning for a Comprehensive Bridge Safety Assurance Program. Transportation Research Record, 1290, 39-50, 1991.

[2] J.L. Briaud, C.F.K. Ting, H.C. Chen, R. Gudavalli, S. Perugu, G. Wei, SRICOS: Prediction of Scour Rate in Cohesive Soils at Bridge Piers. Journal of Geotechnical and Geoenvironmental Engineering, 125(4),237-246, 1999.

[3] K. Wardhana, F.C. Hadipriono, Analysis of Recent Bridge Failures in the United States. Journal of Performance of Constructed Facilities, 17(3), 144-150, 2003. https://doi.org/10.1061/(ASCE)0887-3828(2003)17:3(144)

[4] P.F. Lagasse, P.E. Clopper, L.W. Zevenberge, L.G. Girald, Countermeasures to protect bridge piers from scour. NCHRP Report 593, Trasportation research board, Natinal research council, 2007.

[5] R. Lamb, P. Garside, P. Raghav, J.W. Hall, A Probabilistic Model of the Economic Risk to Britain's Railway Network from Bridge Scour During Floods. Risk Analysis, 39(11), 2457-2478, 2019. https://doi.org/10.1111/risa.13370

[6] A. Pizarro, S. Manfreda , E. Tubaldi, The science behind scour at bridge foundations: A review. Water, 12(2), 374, 2020.

[7] A.M. Kirby, M. Roca, A. Kitchen, M. Escarameia, O.J. Chesterto, Manual on Scour at Bridges and Other Hydraulic Structures - Second Edition. CIRIA742, 2015.

[8] Y.N. Kishore, S.N. Rao, J.S. Mani, The Behavior of Laterally Loaded Piles Subjected to Scour in Marine Environment. KSCE Journal of Civil Engineering, 13(6), 403-406, 2009. https://doi.org/10.1007/s12205-009-0403-2

[9] F. Li, T. Peisan, W. Lixian, C. Mingsheng, Investigation on Lateral Bearing Capacity of Monopile under Combined Vertical-Lateral Loads and Scouring Condition. Marine Georesources and Geotechnology, 1521-0618, 2020.

https://doi.org/10.1080/1064119X.2020.1719562

[10] S. Foti, D. Sabia, Influence of Foundation Scour on the Dynamic Response of an Existing Bridge. Journal of Bridge Engineering, 16(2), 295-304, 2011.

https://doi.org/10.1061/(ASCE)BE.1943-5592.0000146 
[11] A. Zarafshan, A. Iranmanesh, F. Ansari, Vibration-Based Method and Sensor for Monitoring of Bridge Scour. Journal of Bridge Engineering, 17(6), 829-838, 2012. https://doi.org/10.1061/(ASCE)BE.1943-5592.0000362

[12] T. Bao, R.A. Swartz, S. Vitton, Y.Sun, C. Zhang, Z. Liu, Critical Insights for Advanced Bridge Scour Detection Using the Natural Frequency. Journal of Sound and Vibration, 386, 116-133, 2017. https://doi.org/10.1016/j.jsv.2016.06.039

[13] L.J. Prendergast, K. Gavin, D. Hester, Isolating the Location of Scour-Induced Stiffness Loss in Bridges Using Local Modal Behaviour. Journal of Civil Structural Health Monitoring, 7, 483-503, 2017. https://doi.org/10.1007/s13349-017-0238-3

[14] K.K.G.K.D. Kariyawasam, P.R.A Fidler, J.P. Talbot, C.R. Middleton, Field Deployment of an Ambient Vibration - Based Scour Monitoring System at Baildon Bridge, UK. International Conference on Smart Infrastructure and Construction, Cambridge, England, 711-719, July 8-10, 2019. https://doi.org/10.1680/icsic.64669.711

[15] F. Gara, M. Regni, D. Roia, S. Carbonari, F. Dezi, Evidence of coupled soil-structure interaction and site response in continuous viaducts from ambient vibration tests. Soil Dynamics And Earthquake Engineering, 120, 408-422, 2019.

[16] V. Nicoletti, D. Arezzo, S. Carbonari, F. Dezi, F. Gara. Measurements of ambient vibrations for a cable-stayed bridge including the soil-foundation system. XI International Conference on Structural Dynamics (EURODYN), Athens, Greece, November 23-26, 2020. https://doi.org/10.47964/1120.9138.20136

[17] E. Tubaldi, R. Lupo, S. Mitoulis, S. Argyroudis, F. Gara, L. Ragni, S. Carbonari, F. Dezi, Field tests on a soil-foundation-structure system subjected to scour. XVII CONVEGNO ANIDIS, Ascoli Piceno, September 15 - October 19, 2019.

[18] X. Guo, Seismic Viulnerability Analysis of Scoured Bridge Systems. Doctoral dissertation. University of Missouri, Kansas City, 2014.

[19] P. Zampieri, M.A. Zanini, F. Faleschini, L. Hofer, C. Pellegrino, Failure Analysis of Masonry Arch Bridges Subject to Local Pier Scour. Engineering Failure Analysis, 79, 371-384, 2017. https://doi.org/10.1016/j.engfailanal.2017.05.028

[20] A. Alipour, B. Shafei, Performance Assessment of Highway Bridges Under Earthquake and Scour Effects. 15th World Conference of Earthquake Engineering, Lisbon, Portugal, September 24-28, 2012.

[21] S. Banerjee, G.G. Prasad, Seismic Risk Assessment of Reinforced Concrete Bridges in Flood-Prone Regions. Structure and Infrastructure Engineering, 9(9), 952-968, 2013. https://doi.org/10.1080/15732479.2011.649292

[22] B. Zhu, X. Wu, Y. Wang, Y. Chen, Centrifuge Modeling for Seismic Response of FixedEnd Model Piles Considering Local Scour. Journal of Waterway, Port, Coastal, and Ocean Engineering, 146(6), 04020041, 2020. https://doi.org/10.1061/(ASCE)WW.1943-5460.0000604

[23] Z. Hryniewicz, Dynamic Response of a Rigid Strip on an Elastic Half-Space. Computer Methods in Applied Mechanics and Engineering, 25(3), 355-64, 1981.

https://doi.org/10.1016/0045-7825(81)90038-4 
[24] G. Gazetas. Formulas and Charts for Impedances of Surface and Embedded Foundations. Journal of Geotechnical Engineering, 117(9), 1363-1381, 1991. https://doi.org/10.1061/(ASCE)0733-9410(1991)117:9(1363)

[25] J. Zhang, Y. Tang, Evaluating Radiation Damping of Shallow Foundations on Nonlinear Soil Medium for Soil-Structure Interaction Analysis of Bridges. $22^{\text {nd }}$ US-Japan Bridge Engineering Workshop, Seattle, WA, October 23-28, 2006.

[26] Dassault Systèmes Simulia. Abaqus 2018.

[27] R.L Kuhlemeyer, J. Lysmer, Finite Element Method Accuracy for Wave Propagation Problems. Journal of the Soil Mechanics and Foundations Division, 99(5):421-7, 1973.

[28] C. Volpini, J. Douglas, A.H. Nielsen, Guidance on Conducting 2D Linear Viscoelastic Site Response Analysis Using a Finite Element Code. Journal of Eartquake Engineering, 2019. https://doi.org/10.1080/13632469.2019.1568931

[29] G.J.C.M. Hoffmans, H.J.Verhei, Scour Manual. Balkema, Rotterdam, Netherlands, 1997. https://doi.org/10.1201/9780203740132

[30] S. Tileylioglu, J.P. Stewart, R.L. Nigbor. Dynamic Stiffness and Damping of a Shallow Foundation from Forced Vibration of a Field Test Structure. Journal of Geotechnical and Geoenvironmental Engineering, 137(4), 344-53, 2011. https://doi.org/10.1061/(ASCE)GT.1943-5606.0000430

[31] A. Maravas, G. Mylonakis, D.L. Karabalis, Simplified Discrete Systems for Dynamic Analysis of Structures on Footings and Piles. Soil Dynamics and Earthquake Engineering, 61-62, 29-39, 2014. https://doi.org/10.1016/j.soildyn.2014.01.016

[32] J. Fu, J. Liang, M. Todorovska, M. Trifunac, Soil-Structure System Frequency and Damping: Estimation from Eigenvalues and Results for a 2D Model in Layered HalfSpace. Earthquake Engineering and Structural Dynamics, 47, 2055-2075, 2018. https://doi.org/10.1002/eqe.3055

[33] D. Pitilakis, E. Rovithis, A. Anastasiadis, A. Vratsikidis, M. Manakou. Field Evidence of SSI from Full-Scale Structure Testing. Soil Dynamics and Earthquake Engineering, 112, 89-106, 2018. https://doi.org/10.1016/j.soildyn.2018.04.024 